\title{
25 Research Square \\ Photodynamic inactivation of Botrytis cinerea for a safe pest management of grapevine
}

\author{
Veronica Ambrosini \\ Universite de Limoges \\ Mohammad Issawi \\ Universite de Limoges \\ Vincent Sol \\ Universite de Limoges \\ Catherine Riou ( $\nabla$ catherine.riou@unilim.fr) \\ Universite de Limoges
}

\section{Research}

Keywords: Anionic porphyrin, APDT, Botrytis cinerea, grapevine, leaves, photosensitizer, TPPS

Posted Date: April 9th, 2020

DOl: https://doi.org/10.21203/rs.3.rs-21649/v1

License: (9) This work is licensed under a Creative Commons Attribution 4.0 International License. Read Full License 


\section{Abstract}

Botrytis cinerea is a necrotic fungal plant pathogen responsible for the gray mold disease on more than $200 \mathrm{crops}$, including grapevine. Due to its genetic plasticity, this fungus presents a strong resistance to a large spectrum of fungicides. Thus, new fighting strategies against $B$. cinerea are urgently needed. In this context, antimicrobial photodynamic treatment (APDT) was considered. APDT involves the use of a photosensitizer that generates reactive oxygen species upon illumination. Tetra-4-sulfonatophenyl porphyrin tetra-ammonium (TPPS) was tested on $B$. cinerea; upon light exposure. $1.5 \mu \mathrm{M}$ TPPS was shown to completely inhibit mycelial growth. A concentration of $12.5 \mu \mathrm{M}$ TPPS was tested on three genetic background clones from Chardonnay, Merlot and Sauvignon, grown in vitro for 2 months. Treated root apparatus of the three backgrounds was able to increase thiol production as a molecular protection against photoactivated TPPS, leading to a normal phenotype as compared with control plantlets. Finally, two-month-old grapevine leaves were infected with four-day-old mycelium of $B$. cinerea pre-incubated or not with TPPS. The pre-treated mycelium was unable to infect the isolated leaves of any of the three grapevine varieties after $72 \mathrm{~h}$ growth when subjected to a $16 \mathrm{~h}$ photoperiod, contrary to untreated mycelium. These results on fungus, plantlets and Botrytis-grapevine leaves, in contact with a very low concentration of TPPS, suggest a strong potential of photo-treatment against Botrytis mycelium for future agricultural practices in vineyard or other cultures.

\section{Introduction}

The great challenge of agriculture is to produce sufficient food for the ever-growing world population. Since the $60 \mathrm{~s}$, to access this performance, agri-business practices that include excessive uses of pesticides and fertilizers are becoming the main cause of soil, water and air pollution, as well as loss of fauna and flora biodiversity (Carvalho 2017; Meftaul et al. 2019). Moreover, this industrial agriculture triggers major public health problems such as infertility, cancers and child malformations. Aware of the need to reduce all these dramatic environmental damages, the European Union introduced the directive 2009/128/EC to reduce the use of pesticides.

To fight off plant competitors and pathogens, new approaches are necessary for safe practices in agriculture such as genetically modified plants, genetic improvements, as well as organic and integrated agriculture (Kiley-Worthington 1981; Key et al. 2008). The photodynamic treatment is a general and new concept with a large spectrum of applications for animal and plant cells, plant and animal pathogens, as well as microorganisms (Ben Amor and Jori 2000; Jori and Brown 2004; Donnely et al. 2008; Maisch 2009; Almeida et al. 2011; Jori 2011; Alves et al. 2015; Liu et al. 2015; Hamblin 2016; Kashef et al. 2017; Issawi et al. 2018a; Ambrosini et al. 2019). Thus, photodynamic treatment could represent an innovative and powerful strategy to fight off plant competitors and pathogens in future agricultural practices (Issawi et al. 2018a). One of the key actors of APDT is a molecule called a photosensitizer (PS). When irradiated with light, this molecule produces reactive oxygen species that are toxic for cells (Dai et al. 2009). By contrast, most PSs present low levels of cytotoxicity or genotoxicity in the dark (Luksiene et al. 2004; Donnelly et al. 2008). Furthermore, biological applications are best conducted with water-soluble PSs 
which are ideally prone to quick photodegradation, thus avoiding a buildup of toxicity. PSs are classified in many groups such as porphyrins, chlorins, coumarins, furocoumarins, phthalocyanines and phenothiaziniums. Porphyrins and chlorins such as chlorophyllin, have been shown to be very effective against bacteria on kiwi leaves tested in vitro (Jesus et al. 2018; Glueck et al. 2019). Coumarins, furocoumarin and phenothiazinium were shown to be active against the plant-infecting fungi Colletrichum acuratum and Aspergillus nidulans (De Menezes et al. a, b; 2014; Fracarolli et al. 2016). Finally, when tested on Citrus sinensis petals and leaves, methylene blue was able to kill the Colletotrichum abscissum fungus and proved to be harmless to plant organs; in addition, this treatment did not induce any secondary resistance (Gonzales et al. 2017)

Previous research works explored the in vitro phenotypical and molecular responses of Arabidopsis and tomato plantlets to the photodynamic stress induced by an exogenous supply of PS (Guillaumot et al. 2016; Issawi et al. 2018b). The cationic tetra (N-methylpyridyl) porphyrin, either free base or zinccomplexed, tested at $3.5 \mu \mathrm{M}$, inflicted harmful effects on both 14-day-old Arabidopsis and tomato plantlets. Nevertheless, while Arabidopsis plantlets were killed, tomato plantlets could be rescued after a 14 day-treatment (Guillaumot et al. 2016). Surprisingly, the anionic porphyrin tetra-4sulfonatophenylporphyrin tetra-ammonium (TPPS) did not provoke any harmful effect on both plantlets even at concentrations as high as $50 \mu \mathrm{M}$ (Guillaumot et al. 2016; Issawi et al. 2018b). With the aim to develop APDT for agriculture applications, TPPS could be a good candidate because of its low toxicity for plants. Moreover, TPPS remains negatively charged in many chemical environments even under acidic $\mathrm{pH}$ and does not aggregate in solution, allowing it to easily permeate cells through cell walls and membranes (Leroy-Lhez et al. 2019; Issawi et al. 2019). Therefore, we hypothesized that TPPS could be a good PS candidate to kill the plant pathogen $B$. cinerea and be a safe option for grapevine (Vitis vinifera L.) explants.

B. cinerea is frequently responsible for drastic reductions in crop yields at harvest and for reducing wine quality (Rosslenbroich and Stuebler 2000; Williamson et al. 2007). This fungus displays very strong resistance to many fungicides, due to its genetic plasticity which confers its diversity in morphology, mycelial growth, sporulation and virulence (Movahedi and Heale 1990; Yourman et al. 2001; Valiuskaite et al. 2010; Nakajima and Akutsu 2014; Nakamura and Iwai 2019). For the Integrated Pest management, the grapevine's susceptibility to $B$. cinerea can be considered an essential management indicator (Galet 1988; Dry and Gregory 1988; Marois et al. 1992; Kogan 1998; Dubos 2002; Fermaud et al. 2011). According to the classification proposed by Dubos 2002 and Fermaud et al. 2011, Chardonnay and Sauvignon are highly susceptible to $B$. cinerea infection whereas the Merlot variety is more resistant. Furthermore, these three varieties are listed in the top 10 most cultivated and famous grapevines for wine production in the world (Anderson 2013).

Therefore, as a first and necessary step, TPPS was tested separately on the three grapevine backgrounds and on Botrytis mycelium with the aim of killing the plant pathogen without affecting plantlet growth and development. As a second and final step, grapevine leaves infected with Botrytis mycelium were tested with and without TPPS pre-treatment. 


\section{Material And Methods \\ Photosensitizer}

5,10,15,20-(tetra-4-sulfonatophenyl) porphyrin tetra-ammonium (TPPS) was purchased from PorphyChem (Dijon, France). The stock solution $(1 \mathrm{mM})$ was prepared in distilled water and kept in the dark at room temperature for 2 weeks.

\section{Botrytis cinerea culture}

The B. cinerea strain (UBOCC-A-117017) used in this study was isolated from infected tomatoes and provided by Dr Amélie Weill (Université de Bretagne Occidentale, Brest, France). The culture was maintained on potato dextrose agar (PDA). The growth curve of $B$. cinerea was performed as follows: a plug ( $0.6 \mathrm{~cm}$ diameter) of two-week old $B$. cinerea mycelium was placed in the middle of plates containing PDA medium supplemented with or without TPPS in the concentration range $0.5-3.5 \mu \mathrm{M}$. TPPS was added to the PDA medium just after autoclaving $\left(120^{\circ} \mathrm{C}, 20 \mathrm{~min}\right)$. Plates were incubated at $22{ }^{\circ} \mathrm{C}$, either in the dark or subjected to a photoperiod of 16 hours. Daily measurements of the diameter of the fungus were performed and reported to draw the growth curves.

\section{Grapevine clone culture}

Chardonnay (clone 7535) was provided by Pr. Clément (Université de Reims, Champagne-Ardenne, France). Sauvignon (clone 379) and Merlot (clone 373) were provided by the Institut Français de la Vigne et du Vin (Bordeaux, France). Intermodal explants of grapevine were dissected and placed in glass tubes or jars containing half Chée and Pool medium, and $2 \%(\mathrm{w} / \mathrm{v})$ sucrose-solidified medium ( $\mathrm{pH}$ 5.9) for 2 months. TPPS was added to the medium after autoclaving. Chée and Pool medium was purchased from Duchefa Biochemistry (Haarlem, Holland). The cultures were then exposed to white light (photon flux density of $120 \mu \mathrm{mol} \cdot \mathrm{m}^{-2} \cdot \mathrm{s}^{-1}$ ) for 16 hours and the temperature was maintained at $24{ }^{\circ} \mathrm{C}$.

\section{Infection of young leaves with $B$. cinerea}

Two-month-old grapevine leaves and four-day-old mycelium plug ( $0.6 \mathrm{~cm}$ diameter) were used to perform the experiment. Mycelium discs were firstly incubated in 12.5 or $50 \mu \mathrm{M}$ TPPS in the dark and gently stirred for 8 hours at $22^{\circ} \mathrm{C}$. Fungus discs were then placed on the upper leaf epidermis of the grapevine (Chardonnay, Merlot and Sauvignon). The co-cultures were monitored daily and photographed using a Leica stereomicroscope.

\section{MTT assay}

A 3-[4,5-dimethylthiazol-2-yl]-2,5-diphenyltetrazolium bromide (MTT) assay was carried out on the fungus mycelium, that was treated with TPPS or not, and had grown for 4 days under photoperiod. The MTT assay was performed to quantify the mitochondrial activity of mycelial cells. The fungal samples were 
frozen in liquid nitrogen and were ground to a powder. $1 \mathrm{~mL}$ of $0.1 \%(\mathrm{~m} / \mathrm{v})$ MTT solution was added to $150 \mathrm{mg}$ of powder. Samples were left in the dark and stirred for 3 hours at room temperature. The suspension was centrifuged at $4,000 \times \mathrm{g}$ for $10 \mathrm{~min}$. Supernatant was discarded and $1 \mathrm{~mL}$ of isopropanol was added to the pellet. Samples were vortexed and centrifuged at $4,000 \times \mathrm{g}$ for $10 \mathrm{~min}$. Absorbance was read at $590 \mathrm{~nm}$.

\section{Determination of malondialdehyde content}

Approximately $150 \mathrm{mg}$ of fresh or frozen fungal material were ground in liquid nitrogen. $1.5 \mathrm{~mL}$ of $20 \%$ (w/v) TCA was added onto the powder. The mixture was centrifuged at $13,000 \times \mathrm{g}$ at $4{ }^{\circ} \mathrm{C}$ for $20 \mathrm{~min}$. The supernatants were analyzed for their malondialdehyde (MDA) content as described by Hodges (1999) with minor modifications described in Issawi et al. (2018b).

\section{Hydrogen peroxide quantification}

The measurement of Hydrogen peroxide $\left(\mathrm{H}_{2} \mathrm{O}_{2}\right)$ was performed according to a modified procedure (Pandey 2013). $1 \mathrm{~mL}$ of extraction buffer ( $50 \mathrm{mM}, \mathrm{pH}$ 7.8) was added to fresh samples such as mycelium, plantlets or in vitro isolated leaves. The composition of the extraction buffer added to the mycelium samples was $1 \mathrm{mM}$ EDTA, 1\% (w/v) PVP, 10\% (v/v) glycerol and $1 \mathrm{mM}$ DTT. For the plantlet and the leaf samples, the extraction buffer was almost identical, however PVPP was used in the buffer, instead of PVP. All samples had been frozen in liquid nitrogen and prior to being grounded into a powder. Homogenates were centrifuged at $13,000 \times \mathrm{g}$ at $4{ }^{\circ} \mathrm{C}$ for $20 \mathrm{~min} .335 \mu \mathrm{L}$ of $0.1 \%$ titanium III sulfate $(\mathrm{v} / \mathrm{v})$ dissolved in a solution of $20 \%(\mathrm{w} / \mathrm{v}) \mathrm{H}_{2} \mathrm{SO}_{4}$, and this solution was added to supernatants. Absorbances were read at $415 \mathrm{~nm}$ and $\mathrm{H}_{2} \mathrm{O}_{2}$ levels were expressed as $\mathrm{nM} . \mathrm{g}^{-1}$ protein. Protein concentration was determined by Bradford assay using BSA as standard (Bradford, 1976).

\section{Total Thiol Assay}

Approximately $100 \mathrm{mg}$ of fine powder has been obtained from the samples (fungus, plantlets or in vitro isolated leaves). After grinding in liquid nitrogen, $1 \mathrm{~mL}$ of $0.2 \mathrm{~N} \mathrm{HCl}$ was added to the powder. A centrifugation at $13,000 \times \mathrm{g}$ for 20 min was performed. Afterward, $500 \mu \mathrm{L}$ of the supernatant were neutralized with $400 \mu \mathrm{L} \mathrm{NaOH}(0.2 \mathrm{M})$ and $50 \mu \mathrm{L} \mathrm{NaH} \mathrm{PO}_{4}(0.2 \mathrm{M}) .700 \mu \mathrm{L}$ of $0.12 \mathrm{M} \mathrm{NaH}_{2} \mathrm{PO}_{4}, 6 \mathrm{mM}$ EDTA and $0.1 \mathrm{~mL}$ of $6 \mathrm{mM}$ dithiobis-2-nitro-benzoic acid (DTNB) were added to $200 \mu \mathrm{L}$ of extract. A standard calibration curve was prepared by replacing the extract with $0,5,10,25$ and $50 \mu \mathrm{g} / \mathrm{mL}$ glutathione solutions (total volume $1 \mathrm{~mL}$ ). Absorbance at $412 \mathrm{~nm}$ was read $5 \mathrm{~min}$ after the addition of glutathione or extract.

\section{Environmental Scanning Electronic Microscopy}

Environmental Scanning Electronic Microscopy (ESEM) was performed on B. cinerea mycelium and in vitro isolated leaves after fungus infection. Mycelium grew on plates supplemented or not with TPPS for 4 days under $16 \mathrm{~h}$ photoperiods and was examined under Environmental Scanning Electronic Microscope (ESEM Quanta 450, Felmi-ZFE, Graz, Austria). Sizes of hyphae or branching filaments that constitute the mycelium of the fungus, were measured from ESEM pictures. 
Two-month-old healthy grapevine leaves and leaves infected with $B$. cinerea pre-treated or not with TPPS were examined under ESEM

\section{Confocal microscopy analysis}

Mycelium was cultivated for 4 days on media containing 3.5 $\mu \mathrm{M}$ TPPS in the dark. Data acquisition with a LSM510META Zeiss confocal microscope (Carl Zeiss France, Marly-le-Roi, France) was performed under the spectral acquisition mode for TPPS localization inside the mycelium (excitation at $405 \mathrm{~nm}$, emission detected at $640 \mathrm{~nm}$ ) and under the channel mode for examination of the mycelium.

\section{Statistical Analysis}

All biological experiments were performed at least three times independently. Results were expressed as a mean \pm SD (Standard Deviation). The data were analyzed by t-student test and one-way ANOVA using the PAST free software.

\section{Results}

\section{Mycelium growth}

The effect of three increasing concentrations of TPPS was monitored on B. cinerea mycelium growth under dark and light conditions as described in the material and methods section. As the four curves obtained with or without TPPS in the dark did coincide within the standard deviation, we confirmed that, by itself, TPPS did not exhibit any cyto- and/or genotoxic activity against the fungus (Fig. 1a). Under light and at a low TPPS concentration (1.5 $\mathrm{MM})$, mycelium growth was completely inhibited (Fig. 1b).

Furthermore, $1 \mu \mathrm{M}$ TPPS significantly slowed down mycelium growth under light; however, after a 7 dayculture, the colony reached a size similar to that of the control (Fig. 1b). Therefore, the concentration of $1.5 \mu \mathrm{M}$ of photoactivated TPPS has been chosen as the minimum fungicidal concentration (MFC). As shown by the growth curves in the dark and under light conditions, the fourth day of culture corresponded to the end of the exponential growth phase (Fig. 1). Thus, all further experiments were conducted with 4day old mycelium

\section{Effect of photoactivated TPPS on hyphae morphology}

As mycelium growth was affected by photoactivated TPPS, it was decided to carefully look at the hyphae structure, using ESEM. It has been shown that stressed mycelium often produces spores and could show altered cell elongation (Schumacher 2017). As expected, photoactivated TPPS induced important phenotypic changes of the hyphae, compared with the control that showed very regular hyphae with a well-organized structure (Fig. 2a). In presence of 1.5 $\mu \mathrm{M}$ TPPS, hyphae were notably less organized, exhibited irregular shapes and produced some spores (Fig. 2a). Moreover, the TPPS-treated hyphae presented a reduced width $(1.36 \mu \mathrm{m})$ compared with the control $(4.7 \mu \mathrm{m})$ (data not shown). 


\section{TPPS localization inside mycelial cells}

According to the phenotypical effects observed in TPPS-treated mycelium under light, it was of interest to localize TPPS inside the cells. In tobacco plant cells, TPPS was also tested at $3.5 \mu \mathrm{M}$ and it was the most effective porphyrin PS to induce cell death under a short light period of 5 hours and it was proven to mainly localize in the cell wall (Riou et al. 2014; Issawi et al. 2019). Thus, a similar localization of TPPS was expected in the fungal cells. Surprisingly, TPPS was found inside several cells of four-day-old mycelium (Fig. 2b). This intracellular localization could explain the very strong inhibitory effect of photoactivated TPPS on mycelial growth. As TPPS was located inside cells, this showed that it could cross the cell wall and accumulate in the cell cytoplasm. The multi-layer fungal cell wall is enriched in neutral sugars and proteins and poor in chitin and uronic acids, suggesting a neutral global charge of the cell wall (Cantu et al. 2009). Nevertheless, the Botrytis cell wall composition and its global charge remain controversial. We hypothesized that this neutrality could allow TPPS to cross the fungal cell wall which is completely different from the tobacco cell wall (Cantu et al. 2009; Issawi et al. 2017, 2019).

\section{Biochemical activities of TPPS-treated B. cinerea mycelium}

To gain insight into the effect of photoactivated TPPS on the mycelium, biochemical assays linked to oxidative stress and cell metabolism activity, were conducted. As expected, increases in both $\mathrm{H}_{2} \mathrm{O}_{2}$ and MDA contents were observed in treated mycelium compared to the control, demonstrating at the molecular level that the fungus was stressed (Fig. 3). Metabolic activity, linked to mitochondrial respiration, was monitored with the MTT assay. Indeed, under light, formazan production decreased in the treated hyphae compared with the control, thus explaining the fungal growth inhibition (Fig. 3). While MDA indicated an increase in lipid peroxidation in the presence of photoactivated TPPS, the thiol content provided additional evidence that the fungus was not dead but only under a large amount of stress (Fig. $3)$.

\section{TPPS and grapevine plantlets grown in vitro}

Internodal explants from each variety: Merlot, Sauvignon and Chardonnay, were placed on $12.5 \mu \mathrm{M}$ of TPPS for two months in growth chambers as described in the material and methods section. Each culture was examined during a period of 3-months and the explant sub-culture was performed from two-monthold plantlets. There was no phenotypical difference between the control and the treated plantlets after a one-month culture (Fig. 4). To confirm the absence of the phenotypical effect of photoactivated TPPS, we measured the thiol content in aerial and root organs of treated and control plantlets from the three varieties (Table 1). Thiols are powerful antioxidants and thus, their cellular content is a good indicator of an efficient response to oxidative stress. Roots from the three varieties, that were in contact with photoactivated TPPS, showed a significant increase in the total thiol content compared to the control (Table 1). At the aerial level, while no difference in thiol content was observed in Sauvignon and Merlot, 
there was a significant difference in the total thiol content measured in Chardonnay (Table 1). This could suggest that the Chardonnay variety is more sensitive to photoactivated TPPS than the two other backgrounds although no visible outcome could be seen at the phenotypic level (Fig. 4).

\section{TPPS effect on Botrytis-infected leaves}

The final interest of this work was to put together grapevine, Botrytis and TPPS with the expectations to kill the pathogen without disturbing plants. As a preliminary assay, before the development of a complete plant pathosystem, our antifungal photodynamic treatment was tested on isolated grapevine leaves from two-month-old plantlets. Experiments were conducted as described in the material and methods section, in the growth chamber. The infection was monitored for $72 \mathrm{~h}$. Before $48 \mathrm{~h}$, no change was observed in leaves from the three clones (data not shown). After 48 hours, the untreated $B$. cinerea started to invade the leaf surface of the three varieties. The growth of the mycelium, pre-treated with $12.5 \mu \mathrm{M}$ of TPPS for 8 h, was not completely inhibited (Fig. 5). However, after a $50 \mu \mathrm{M}$ TPPS pre-treatment, the growth of mycelium was totally inhibited on the leaf surface suggesting that the strategy described in this study worked efficiently.

ESEM analysis was conducted on infected leaves. In uninfected leaves, the structure was well-defined and organized (Fig. 6). However, in the infected leaves when Botrytis was not pre-treated with TPPS, the fungus completely invaded the leaves, making the structure unrecognizable (Fig. 6). By contrast, when $B$. cinerea was pre-treated with $50 \mu \mathrm{M}$ of TPPS, ESEM pictures showed a leaf structure almost identical to that of the control confirming the macroscopic phenotype (Fig. 6). It was noticed for the Sauvignon variety, that spores were present in the pre-treated Botrytis suggesting that Sauvignon was more susceptible than the other two varieties.

For further investigation, biochemical assays were performed. $\mathrm{H}_{2} \mathrm{O}_{2}$ quantification, linked to oxidative stress, was conducted for the three leaf conditions and the three varieties after infection or not with TPPS. After a $72 \mathrm{~h}$ treatment, a basal content of $\mathrm{H}_{2} \mathrm{O}_{2}$ was detected in the three leaf varieties, very similar for Chardonnay and Sauvignon leaves and slightly lower for Merlot (Table 2). When the leaves were infected by a 4-day-old $B$. cinerea mycelium, the $\mathrm{H}_{2} \mathrm{O}_{2}$ content significantly increased for the three varieties especially for Sauvignon (more than 3.5 fold higher than the control leaf) explaining its strong susceptibility to Botrytis (Table 2). B. cinerea is a necrophytic fungus that induces ROS production that contributes to plant cell destruction during its infection (Choquer et al. 2007). Therefore, an increase in $\mathrm{H}_{2} \mathrm{O}_{2}$ production in all leaf types in contact with Botrytis was expected. Concerning the leaves infected by the fungus pre-treated with $50 \mu \mathrm{M}$ TPPS for $8 \mathrm{~h}$, no significant difference was observed between Chardonnay and Merlot leaves compared to leaves infected by the fungus. No signs of infection were observed after $72 \mathrm{~h}$ culture (Fig. 5 and Table 2). Botrytis cinerea, pre-treated with TPPS, was no longer able to induce a high production of $\mathrm{H}_{2} \mathrm{O}_{2}$ in Sauvignon leaves (Table 2). The $\mathrm{H}_{2} \mathrm{O}_{2}$ content nearly reached the basal level detected in the control Sauvignon leaves (Table 2). As a response to this $\mathrm{H}_{2} \mathrm{O}_{2}$ production detected in the leaves induced by Botrytis, and to gain insight into the leaf's proper response, we 
measured the total thiol content in leaves that were subjected to the three different treatments. Thiols are well known antioxidants and are considered as a primary and strong defense to infection (Ulrich and Jakob 2019). For Chardonnay and Merlot isolated leaves, no significant difference was observed between the control, infected leaves and infected leaves pre-treated with TPPS (Table 2). A significant increase in thiol content was only observed for Sauvignon leaves between the control and the infected leaves. This result suggested that Sauvignon leaves were able to fight against the fungus infection with a thiol induced response (Table 2). According to our $\mathrm{H}_{2} \mathrm{O}_{2}$ and thiol content results and what has been previously published in literature, we confirm that Sauvignon was more susceptible to $B$. cinerea infection, compared to Merlot and Chardonnay (Dubos 2002; Fermaud et al. 2011). Nevertheless, we also confirm that our pretreatment with TPPS inhibited Botrytis growth on leaves for each variety. These results are promising for the development of APDT treatments in agriculture (Fig. 5 and 6).

\section{Discussion}

B. cinerea is a very serious problem in a large variety of plants. This fungus is able to infect leaves, stems, flowers and fruit, causing severe damages and commercial losses in agriculture. In vineyards, the fungus induces several deleterious effects on both quality and quantity of vine production. Despite all the damage it can cause, under specific weather conditions, its growth on grapes induces noble rot that gives rise to sweet wine.

However, the fight against this pathogen remains a daily struggle especially for fruit production in summer or fall. For more than 50 years, the use of specific fungicides has largely been envisaged and in that time, Botrytis had to find coping strategies. As a consequence, fungicide treatments gradually became inefficient, even the famous $\mathrm{CuSO}_{4}$ solution also known as 'Bordeaux mixture' lost its effectiveness against fungal pathogens (Leroux et al 2002; Hahn 2014). Moreover, the copper divalent ion, also toxic for plants, contributed to soil pollution (Fernandes and Henriques 1991; Borkow and Gabbay 2005).

Therefore, new strategies against fungi are urgently needed. Wang et al. (2010) used naturally occurring eugenol (EC50 value of $235 \mu \mathrm{M}$ for $B$. cinerea). This was found to mainly affect fungal mycelium growth rather than the germination of spores as shown in previous reports on fungicides, such as carbendazim and N-phenyl carbamates (Sherald et al. 1973; Suzuki et al. 1984).

In a similar way, Fleurat-Lessard et al. (2011) discovered a strategy whereby they investigated the potential of $\mathrm{FeSO}_{4}$ and found that the sulfate anion determines the inhibition of mycelium growth in pathogenic fungi that is similar to $B$. cinerea at high concentrations (range of $0.5-20 \mathrm{mM}$ ). They also tested different iron salts and found that those with bromide, chloride and sulfate anions showed the best antifungal activity. In particular, the addition of an ammonium counterion to the sulfate moiety contributed to the inhibition of mycelium growth in the pathogenic fungus Eutypa lata, an ascomycete like B.cinerea. 
Therefore, taking these results from previous works into account (Fleurat-Lessard et al. 2011; Guillaumot et al. 2016; Issawi et al. 2018b; 2019), we decided to test TPPS, a molecule that presents four external sulfonate groups linked with a tetrapyrrole ring. Indeed, TPPS with an ammonium counterion could be as an excellent antifungal candidate. Moreover, it was demonstrated that TPPS remains negatively charged in a large array of chemical environments, even under acidic $\mathrm{pH}$ and does not aggregate in media, allowing it to diffuse through cell walls and membranes more easily (Leroy-Lhez et al. 2019; Issawi et al. 2019). Therefore, this PS was thought as an excellent candidate for APDT.

Under white light, TPPS at a very low concentration $(\mathrm{MFC}=1.5 \mu \mathrm{M})$ induced a severe inhibition of $B$. cinerea mycelium growth which led to death. We did not succeed to rescue the mycelium after this treatment. To our knowledge, there is little to no information available on the fungistatic or fungicidal effect of light-activated photosensitizers on B. cinerea (Imada et al 2014). The first step was to investigate whether the anionic porphyrin was able to induce any changes in the mycelium structure. In the previous study, it was shown that the structure of the $B$. cinerea hyphae changed after treatment with antibiotics, eugenol, FeSO4 and tea tree oil (Šašek and Musilek. 1974; Wang et al. 2010; Fleurat-Lessard et al. 2011; Shao et al. 2013). We found that TPPS also induces a structural change on the fungus. More specifically, the structure of the PS-treated fungus was thinner than the structure of the control. The treated mycelium produced spores implying that the fungus was under stress. Further analyses, such as the $\mathrm{H}_{2} \mathrm{O}_{2}$ content, MDA, MTT, total thiols and microscopy analysis, confirmed fungus stress to the point of dying. Our findings proved that TPPS, due to its characteristics, could be a valid alternative to classic fungicides (Leroy-Lhez et al. 2019).

The grapevine varieties studied were Chardonnay, Merlot and Sauvignon. The choice of these three varieties was due to their different susceptibility to B. cinerea (Dubos 2002; Fermaud et al 2011). Furthermore, as expected and according to our previous studies (Guillaumot et al. 2016; Issawi et al. 2018b), TPPS did not induce any phenotypical or biochemical modification of the three grapevine plantlets. In addition, this TPPS concentration $(12.5 \mu \mathrm{M})$ was approximately ten times higher than the minimal concentration inhibiting the mycelium growth $(1.5 \mu \mathrm{M})$; thus, the strategy presented in this article could work against pathogens without altering plant growth and development.

The final aim was to demonstrate TPPS efficiency against $B$. cinerea in two-month-old infected grapevine leaves to validate the hypothesis of mimicking a pathosystem. The in vitro cultures and artificial system indeed demonstrated the potential of our strategy. ESEM images from infected leaves, of the three grapevine varieties, after $72 \mathrm{~h}$ treatment confirmed that these leaves infected with $B$. cinerea pre-treated with $50 \mu \mathrm{M}$ TPPS were similar to that of the control. For the Sauvignon variety, the presence of spores on infected leaves confirmed that it is more sensitive to the fungus infection than the other two varieties, which is also confirmed by the total thiol assay

\section{Conclusion}


TPPS was able to kill the pathogen $B$. cinerea without harming the grapevine leaves in vitro. Moreover, this molecule does not produce any biochemical or phenotypical changes on the plantlets grown in vitro. These preliminary experiments carried out are indeed promising and, in the future, experiments could be done in a greenhouse and in fields to determine the real potential and efficacy of TPPS against plant pathogens. The results and findings presented herein are also very encouraging because the photodynamic treatment has been developed using a low concentration of PS. Therefore, we show that APDT can be used for the struggle against phytopathogens in the agronomic practices as the PS is effective against plant pathogens and exhibits non-toxic side effects toward plants.

\section{Declarations}

\section{Acknowledgements}

The authors thank Yann Launay and Claire Carrion for ESEM and confocal microscopy analyses, respectively and Dr Michel Guilloton and Dáire J. Gibbons for manuscript editing.

\section{Authors' contributions}

Veronica Ambrosini wrote the manuscript and carried out the experiments in this presented. Catherine Riou prepared the samples and was a major contributor to the writing of the manuscript. Mohammad Issawi and Vincent Sol contributed to the writing and the substantial re-editing of this paper. All authors read and approved the final manuscript.

\section{Adherence to national and international regulations}

Not applicable.

\section{Availability of data and materials}

Data is available in this text and sources of materials used in this paper are described in materials and methods section.

\section{Competing interests}

The authors declare that they have no competing interests. 


\section{Consent for publication}

Not applicable.

\section{Ethics approval and consent to participate}

Not applicable.

\section{Funding}

The research is funded by the Région Nouvelle-Aquitaine.

\section{References}

Almeida A, Cunha A, Faustino MAF, Tome AC, Neves MGPMS (2011) “Porphyrins as antimicrobial photosensitizing agents" in Photodynamic Inactivation of Microbial Pathogens: Medical and Environmental Applications, eds M. R. Hamblin and G. Jori (Cambridge, UK: RCS Publishing) 83-160

Alves E, Faustino MAE, Neves MS, Cunha A, Nadaisc H, Almeida A (2015) Potential applications of porphyrins in photodynamic inactivation beyond the medical scope. Journal of Photochemistry and Photobiology B: Biology 22:34-57

Ambrosini V, Issawi M, Leroy-Lhez S, Riou C (2019) How protoporphyrinogen IX oxidase inhibitors and transgenesis contribute to elucidate plant tetrapyrrole pathway. Journal of Porphyrins and Phthalocyanines 23:419-426

Anderson K (2013) Which wine grape varieties are grown where? Available at www.adelaide.edu.au/press/titles/ winegrapes.

Ben Amor T, Jori, G (2000) Sunlight-activated insecticides: historical background and mechanisms of phototoxic activity. Insect Biochemistry and Molecular Biology 30:915-925 
Borkow G, Gabbay J (2005) Copper as a biocidal tool. Current Medicinal Chemistry 12:2163-2175

Bradford MM (1976) A rapid and sensitive method for the quantitation of microgram quantities of protein utilizing the principle of protein-dye binding. Analytical Biochemistry 72:248-254

Broome JC, English JT, Marois JJ, Latorre BA, Aviles JC (1995) Development of an infection model for Botrytis bunch rot of grapes based on wetness duration and temperature. Phytopathology 85:97-102

Cantu D, Greve LC, Labavitch JM, Powell ALT (2009) Characterization of the cell wall of the ubiquitous plant pathogen Botrytis cinerea. Mycological Research 113: 1396-1403

Carvalho FP (2017) Pesticides, environment, and food safety. Food and Energy Security 6:48-60

Choquer M, Fournier E, Kunz C, Levis C, Pradier JM, Simon A, Viaud M (2007) Botrytis cinerea virulence factors: new insights into a necrotrophic and polyphageous pathogen. FEMS Microbiology Letters 277:110

Ciliberti N, Fermaud M, Roudet J, Languasco L Rossi V (2016) Environmental effects on the production of Botrytis cinerea conidia on different media, grape bunch trash, and mature berries. Australian Journal of Grape and Wine Research 22:262-270

Dai T, Huang YY, Hamblin MR (2009) Photodynamic therapy for localized infections--State of the art. Photodiagnosis and Photodynamic Therapy 6:170-188

de Menezes HD, Pereira AC, Brancini GTP, Leão HC, Massola JNS, Bachmann L, Wainwright M, Bastos JK, Braga GU (2014a) Furocoumarins and coumarins photoinactivate Colletotrichum acutatum and Aspergillus nidulans fungi under solar radiation. Journal of Photochemistry and Photobiology B: Biology 131:74-83 
de Menezes HD, Rodrigues GB, Teixeira SdP, Massola NS, Bachmann L, Wainwright M, Braga GUL (2014b) In vitro photodynamic inactivation of plant pathogenic fungi Colletotrichum acutatum and Colletotrichum gloeosporioides with novel phenothiazinium photosensitizers. Applied and Environmental Microbiology 80:1623-1632

Donnelly RF, McCarron PA, Tunney MM (2008) Antifungal photodynamic therapy. Microbiological Research $163: 1-12$

Dubos B (2002) Maladies cryptogamiques de la vigne. Champignons parasites des organes herbacés et du bois de la vigne (eds Féret, Bordeaux, France)

Dry PR, Gregory GR (1988) Grapevine varieties. In Viticulture, Vol I, Resources in Australia, eds Coombe, B.G and Dry pp 119-138. Australian Industrial Publisher, Adelaide

Fermaud M, Roudet J, Davidou L (2011) Actualisation des connaissances sur la pourriture grise de la vigne : Nuisibilité et épidémiologie. Chambre d'Agriculture de la Gironde

Fernandes JC, Henriques FS (1991) Biochemical, physiological, and structural effects of excess copper in plants. The Botanical Review $57: 246-273$

Fleurat-Lessard P, Dedaldechamp F, Thibault F, Béré E, Roblin G (2011) Antifungal effects of iron sulfate on grapevine fungal pathogens. Scientia Horticulturae 130:517-523

Fracarolli L, Rodrigues GB, Pereira AC, Massola Júnior NS, Silva-Junior GJ, Bachmann et al (2016) Inactivation of plantpathogenic fungus Colletotrichum acutatum with natural plant-produced photosensitizers under solar radiation. Journal of Photochemistry and Photobiology B : Biology 162:402-411

Galet P (1988) Les maladies et les parasites de la vigne Tome 1. (Tec \& Doc Distribution:France). 
Guillaumot D, Issawi M, Da Silva A, Leroy-Lhez S, Sol V, Riou C (2016) Synergistic enhancement of tolerance mechanisms in response to photoactivation of cationic tetra ( $\mathrm{N}$-methylpyridyl) porphyrins in tomato plantlets. Journal of Photochemistry and Photobiology B: Biology 156:69-78

Glueck M, Hamminger C, Fefer M, Liu J, Plaetzer K (2019) Save the crop: Photodynamic inactivation of plant pathogens I: bacteria. Photochemical \& Photobiological Sciences 18:1700-1708

Gonzales JC, Brancini GTP, Rodrigues GB, Silva-Junior GJ, Bachmann L, Wainwright M et al (2017) Photodynamic inactivation of conidia of the fungus Colletotrichum abscissum on Citrus sinensis plants with methylene blue under solar radiation. Journal of Photochemistry and Photobiology B: Biology 176:54-61

Hahn M (2014) The rising threat of fungicide resistance in plant pathogenic fungi: Botrytis as a case study. Journal of Chemical Biology 7:133-141

Hamblin MR (2016) Antimicrobial photodynamic inactivation: a bright new technique to kill resistant microbes. Current Opinion in Microbiology 33:67-73

Hodges DM, DeLong JM, Forney CF, Prange RK (1999) Improving the thiobarbituric acid-reactivesubstances assay for estimating lipid peroxidation in plant tissues containing anthocyanin and other interfering compounds. Planta 207:604-607

Imada K, Tanaka S, Ibaraki Y, Yoshimura K, Ito S (2014) Antifungal effect of 405-nm light on B. cinerea. Letters in Applied Microbiology 59:670-676

Issawi M, Muhieddine M, Girard C, Sol V, Riou C (2017) Unexpected features of exponentially growing Tobacco Bright Yellow-2 cell suspension culture in relation to excreted extracellular polysaccharides and cell wall composition. Glycoconjugate Journal 34:585-590 
Issawi M, Sol V, Riou C (2018a) Plant Photodynamic Stress: What's New? Frontiers in Plant Sciences 9:681-690

Issawi M, Guillaumot D, Sol V, Riou C (2018b) Responses of an adventitious fast-growing plant to photodynamic stress: comparative study of anionic and cationic porphyrin effect on Arabidopsis thaliana. Physiologia Plantarum 162:379-390

Issawi M, Leroy-Lhez S, Sol V, Riou C (2019) Crossing the First Threshold: New Insights into the Influence of the Chemical Structure of Anionic Porphyrins on Plant Cell Wall Interactions and Photodynamic Cell Death Induction. Biochemistry 58: 2188-2197

Jesus V, Martins D, Branco T, Valério N, Neves MGPMS, Faustino MAF et al (2018) An insight into the photodynamic approach versus copper formulations in the control of Pseudomonas syringae pv. actinidiae in kiwi plants. Photochemical \& Photobiological Sciences 17:180-191

Jori G, Brown S (2004) Photosensitized inactivation of microorganisms. Photochemical \& Photobiological Sciences 3:403-405

Jori G (2011) "Antimicrobial photodynamic therapy: basic principles,"in Photodynamic Inactivation of Microbial Pathogens: Medical and Environmental Applications, eds M. R. Hamblin and G. Jori (Cambridge, UK: RCS Publishing): pp 83-160.

Kashef N, Huang YY, Hamblin MR (2017) Advances in antimicrobial photodynamic inactivation at the nanoscale. Nanophotonics 6:853-879

Key S, Ma J K-C, Drake PMW (2008) Genetically modified plants and human health. Journal of the Royal Society of Medicine 101:290-298 
Kiley-Worthington M (1981) Ecological agriculture. What it is and how it works. Agriculture and Environment 6:349-381

Kogan M (1998) Integrated Pest Management: Historical Perspectives and Contemporary Developments. Annual review of entomology 43:243-270

Leroux P, Fritz R, Debieu D, Albertini C, Lanen C, Bach J, Gredt M, Chapeland F (2002) Mechanisms of resistance to fungicides in field strains of $B$. cinerea. Pest Management Science 58:876-888

Leroy-Lhez S, Rezazgui O, Issawi M, Elhabiri M, Calliste CA, Riou C (2019) Why are the anionic porphyrins so efficient to induce plant cell death? A structure-activity relationship study to solve the puzzle. Journal of Photochemistry \& Photobiology A: Chemistry 368:276-289

Liu Y, Qin R, Zaat SAJ, Breukink E, Heger M (2015) Antibacterial photodynamic therapy: overview of a promising approach to fight antibiotic-resistant bacterial infections. Journal of Clinical and Translational Research 1:140-167

Luksiene Z, Peciulyte D, Lugauskas A (2004) Inactivation of fungi in vitro by photosensitization: preliminary results. Annals of Agricultural and Environmental Medicine 11:215-220

Maisch T (2009) A new strategy to destroy antibiotic resistant microorganisms: antimicrobial photodynamic treatment. Mini-Reviews in Medicinal Chemistry 9:974-983

Marois JJ, Bledsoe AM, Bettiga LJ (1992) Bunch rots. Grape Pest Management, 2nd edn, ed. D. L. Flaherty. (University of California, Division of Agriculture and Natural Resources: Oakland, California) pp.63-69

Meftaul I, Venkateswarlu K, Dharmarajan R, Annamalai P, Megharaj M (2019) Pesticides in the urban environment: A potential threat that knocks at the door. Science of the Total Environment 711:134612 
Movahedi S, Heale JB (1990) The roles of aspartic proteinase and endo-pectin lyase enzymes in the primary stages of infection and pathogenesis of various host tissues by different isolates of $B$. cinerea Pers ex. Pers. Physiological and Molecular Plant Pathology 36:303-324

Nair NG, Allen RN (1993). Infection of grape flowers and berries by Botrytis cinerea as a function of time and temperature. Mycological Research 97:1012-1014

Nakajima M, Akutsu K (2014) Virulence factors of Botrytis cinerea. Journal of General Plant Pathology $80: 15-23$

Nakamura M, Iwai H (2019) Functions and mechanisms: polygalacturonases from plant pathogenic fungi as pathogenicity and virulence factors. Journal of General Plant Pathology 85:243-250

Pandey VP, Singh S, Jaiswal N, Awasthi M, Pandey B, Dwivedi UN (2013) Papaya fruit ripening: ROS metabolism, gene cloning, characterization and molecular docking of peroxidase. Journal of Molecular Catalysis B: Enzymatic 98: 98-105

Riou C, Calliste CA, Da Silva A, Guillaumot D, Rezazgui O, Sol V, Leroy-Lhez S (2014). Anionic porphyrin as a new powerful cell death inducer of Tobacco Bright Yellow-2 cells. Photochemical \& Photobiological Sciences 13: 621-625

Rosslenbroich HJ, Stuebler D (2000) Botrytis cinerea history of chemical control and novel fungicides for its management. Crop Protection 19: 557-561

Šašek V, Musílek V (1974) Contribution to the study of morphological changes in filamentous fungi and yeast induced by antibiotics. Zentralblatt für Bakteriologie, Parasitenkunde, Infektionskrankheiten und Hygiene. Zweite Naturwissenschaftliche Abteilung: Allgemeine, Landwirtschaftliche und Technische Mikrobiologie 129:72-81 
Schumacher J (2017) How light affects the life of Botrytis. Fungal Genetics and Biology 106:26-41

Shao X, Cheng S, Wang H, Yu D, Mungai C (2013) The possible mechanism of antifungal action of tea tree oil on Botrytis cinerea. Journal of Applied Microbiology 114:1642-1649

Sherald JL, Ragsdale NN, Sisler HD (1973) Similarities between the systemic fungicides triforine and triarimol. Pesticide Science 4:719-727

Suzuki K, Kato T, Takahashi J, Kamoshita K (1984) Mode of action of methyl N-(3,5-dichlorophenyl)carbamate in the benzimidazole-resistant isolate of $B$. cinerea. Journal of Pesticide Science 9:497-501

Thomas CS, Marois JJ English JT (1988) The effects of wind speed, temperature, and relative humidity on development of aerial mycelium and conidia of Botrytis cinerea on grape. Phytopathology 78:260265

Ulrich K, Jakob U (2019) The role of thiols in antioxidant systems. Free Radical Biology and Medicine 140:14-27

Valdés-Gómez H, Fermaud M, Roudet J, Calonnec A Gary C (2008) Grey mould incidence is reduced on grapevines with lower vegetative and reproductive growth. Crop Protection 27: 1174-1186

Valiuškaitė A, Survilienė E, Baniulis D (2010) Genetic diversity and pathogenicity traits of Botrytis spp. isolated from horticultural hosts. Zemdirbyste-Agriculture 97:85-1392

Wang C, Zhang J, Chen H, Fan Y, Shi Z (2010) Antifungal activity of eugenol against Botrytis cinerea. Tropical Plant Pathology 35:137-143 
Williamson B, Tudzynski B, Tudzynski P, van Kan JAL (2007) Botrytis cinerea: the cause of grey mould disease. Molecular Plant Pathology 8:561-580

Yourman LF, Jeffers SN, Dean RA (2001) Phenotype instability in Botrytis cinerea in the absence of benzimidazole and dicarboximide fungicides. Phytopathology 91:307-315

\section{Tables}

Due to technical limitations, the tables are only available as a download in the supplemental files section.

\section{Figures}



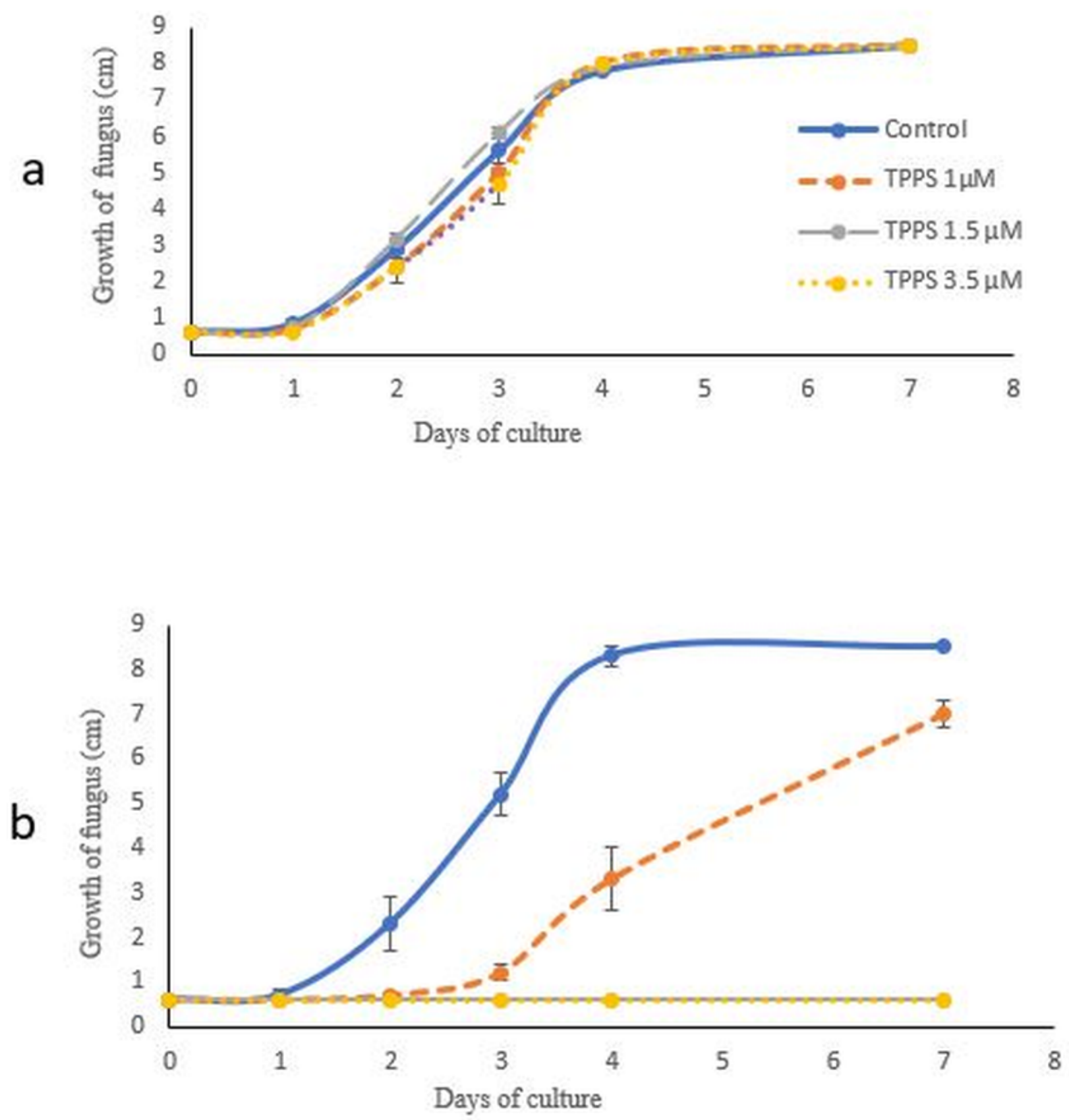

\section{Figure 1}

Growth curves of Botrytis cinerea mycelium (a) in the dark and (b) under $16 \mathrm{~h}$ photoperiod. Growth curve of B. cinerea was performed as follows: a plug of $0.6 \mathrm{~cm}$ diameter was placed in the middle of plates containing PDA medium supplemented with or without TPPS .Three TPPS concentrations: 1, 1.5 and 3.5 $\mu \mathrm{M}$ were tested in the dark and under light. Results are the mean of three independent experiments \pm sd. 

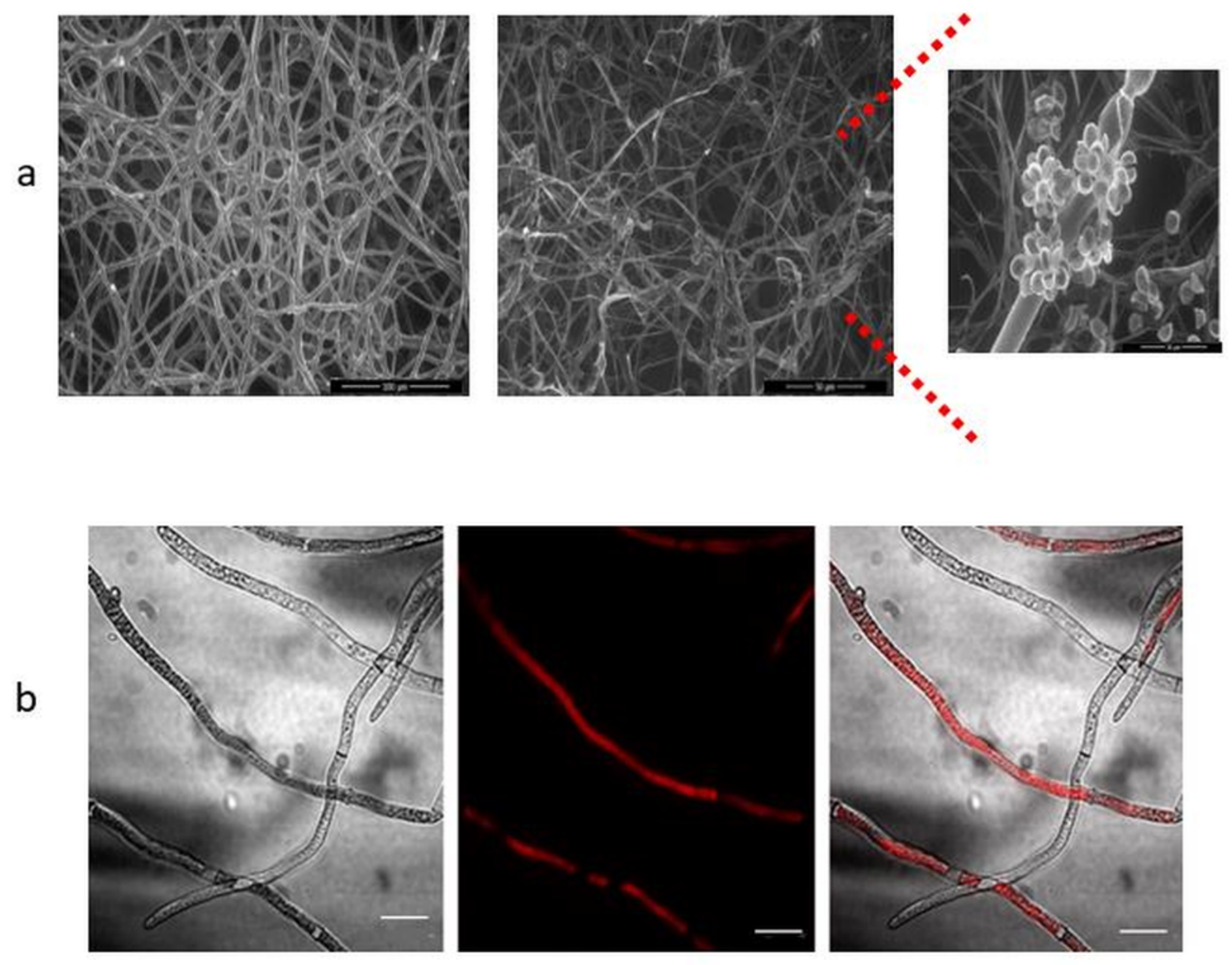

\section{Figure 2}

Microscopic observation of B. cinerea and TPPS localization in mycelial cells. a) B. cinerea visualized under light using environmental scanning electronic microscope. The left picture corresponds to the control hyphae and the middle picture to the irradiated hyphae treated with $1.5 \mu \mathrm{M}$ TPPS. Treated hyphae shows spore formation (right image). b) TPPS localization in B. cinerea hyphae by confocal microscopy. B. cinerea was cultivated for 3 days in presence of $3.5 \mu \mathrm{M}$ TPPS in the dark. Sample was excited at 405 $\mathrm{nm}$ and TPPS detection was performed under spectral acquisition with a peak of emission around 640 nm. Scale bar: $20 \mu \mathrm{m}$. 

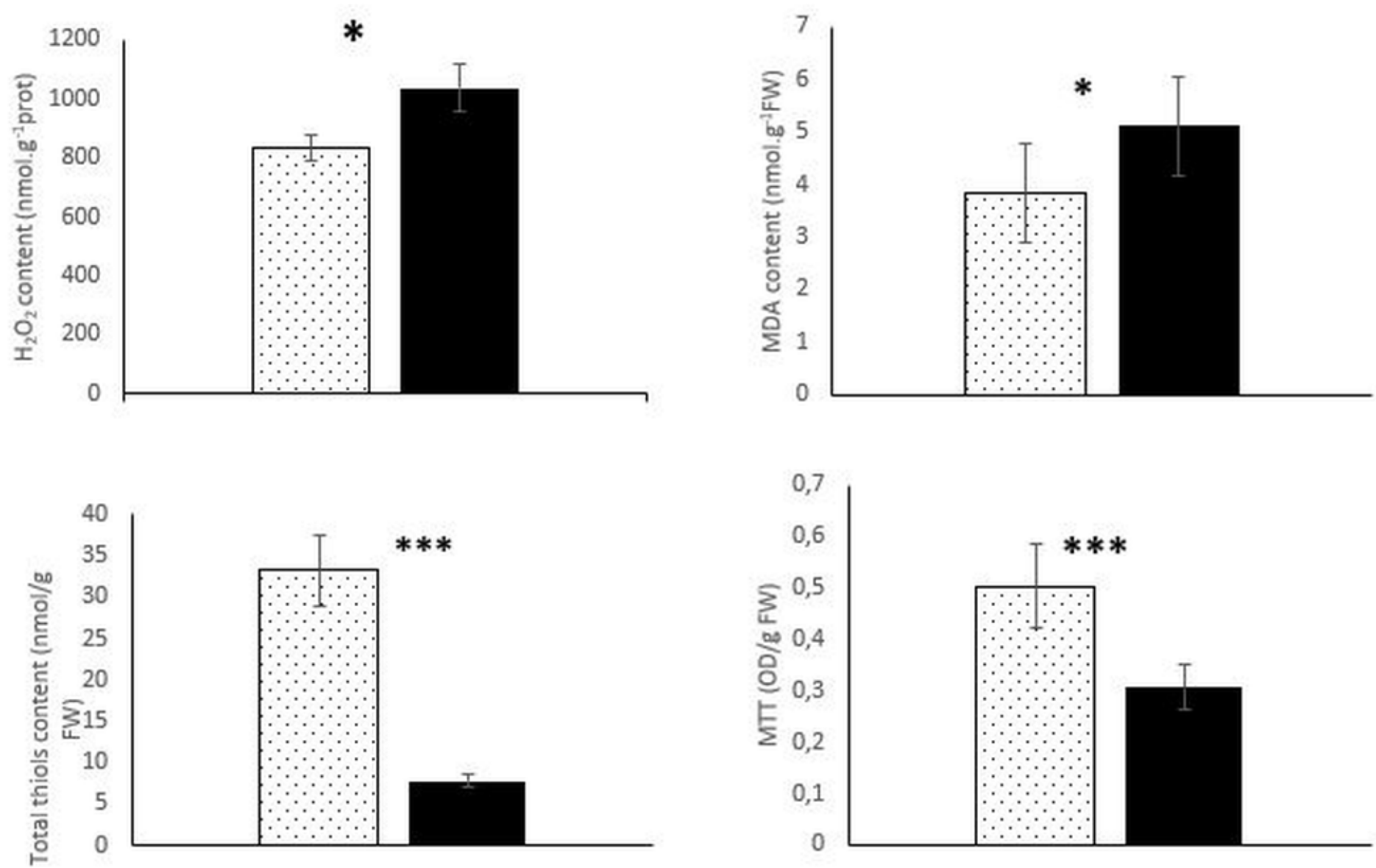

Figure 3

Biochemical activities measured in B. cinerea mycelium under a $16 \mathrm{~h}$ photoperiod white light for 4 days. Hydrogen peroxide ( $\mathrm{H} 2 \mathrm{O} 2)$ production, MDA, total thiol contents and MTT as-say were performed with control mycelium (untreated, dotted box) and mycelium treated with 1.5 $\mu \mathrm{M}$ TPPS (black box). Results are the mean of three independent experiments $\pm s d(*: P<0.05$, $* \star *: P<0.001)$. 


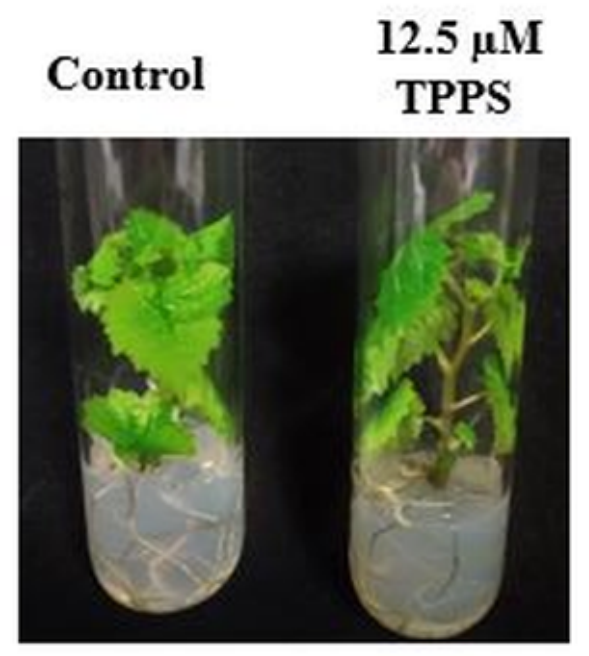

Sauvignon

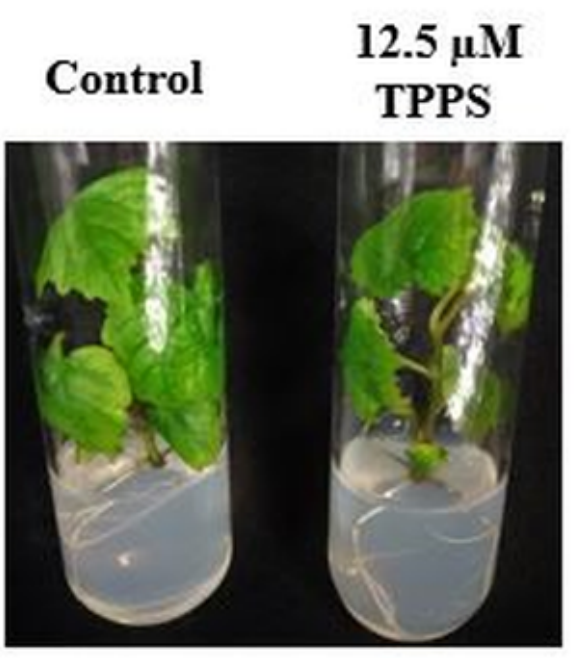

Chardonnay

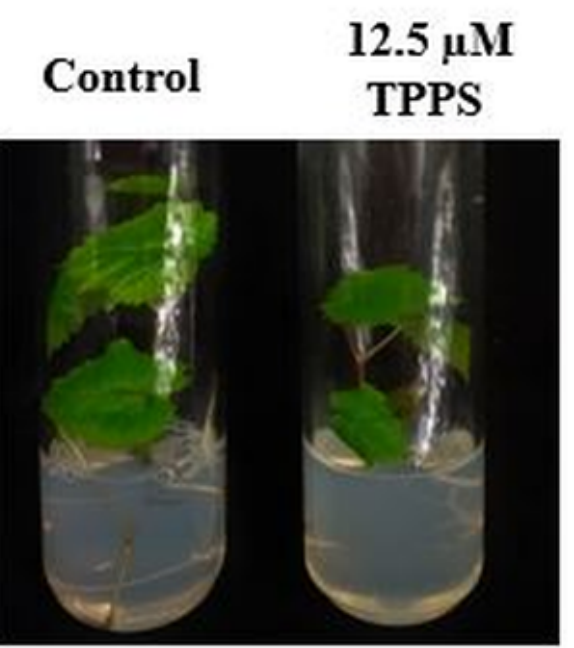

Merlot

\section{Figure 4}

Grapevine varieties growing on control medium and on medium supplemented with $12.5 \mu \mathrm{M}$ TPPS. Pictures correspond to plantlets from each variety, cultured during one month in glass tubes containing control medium (left) or medium with $12.5 \mu \mathrm{M}$ TPPS (right).

展

\section{Figure 5}

TPPS pre-treatment of B. cinerea leads to inhibition of mycelial growth on grapevine leaves. Pictures were taken after a 72 hour infection of B. cinerea. Isolated leaves from the three varie-ties, without any contact with Botrytis (upper panel). On the three other panels, 4-day-old Botry-tis mycelium plugs were placed on isolated leaves. Before contact with isolated leaves, the plugs were pre-incubated or not with 12.5 or 50 $\mu \mathrm{M}$ TPPS for 8 hours under dark conditions. Subse-quent to pretreatment with $12.5 \mu \mathrm{M}$ TPPS, mycelium growth was reduced, but infection was not inhibited. The lower panel corresponds to mycelium pretreatment with $50 \mu \mathrm{M}$ TPPS: B. cinerea was no longer able to invade the leaf surface. The circular plugs correspond to the $6 \mathrm{~mm}$ myceli-um disc placed on the leaf surface at the beginning of the experiments. Scale bar: $2 \mathrm{~mm}$ 


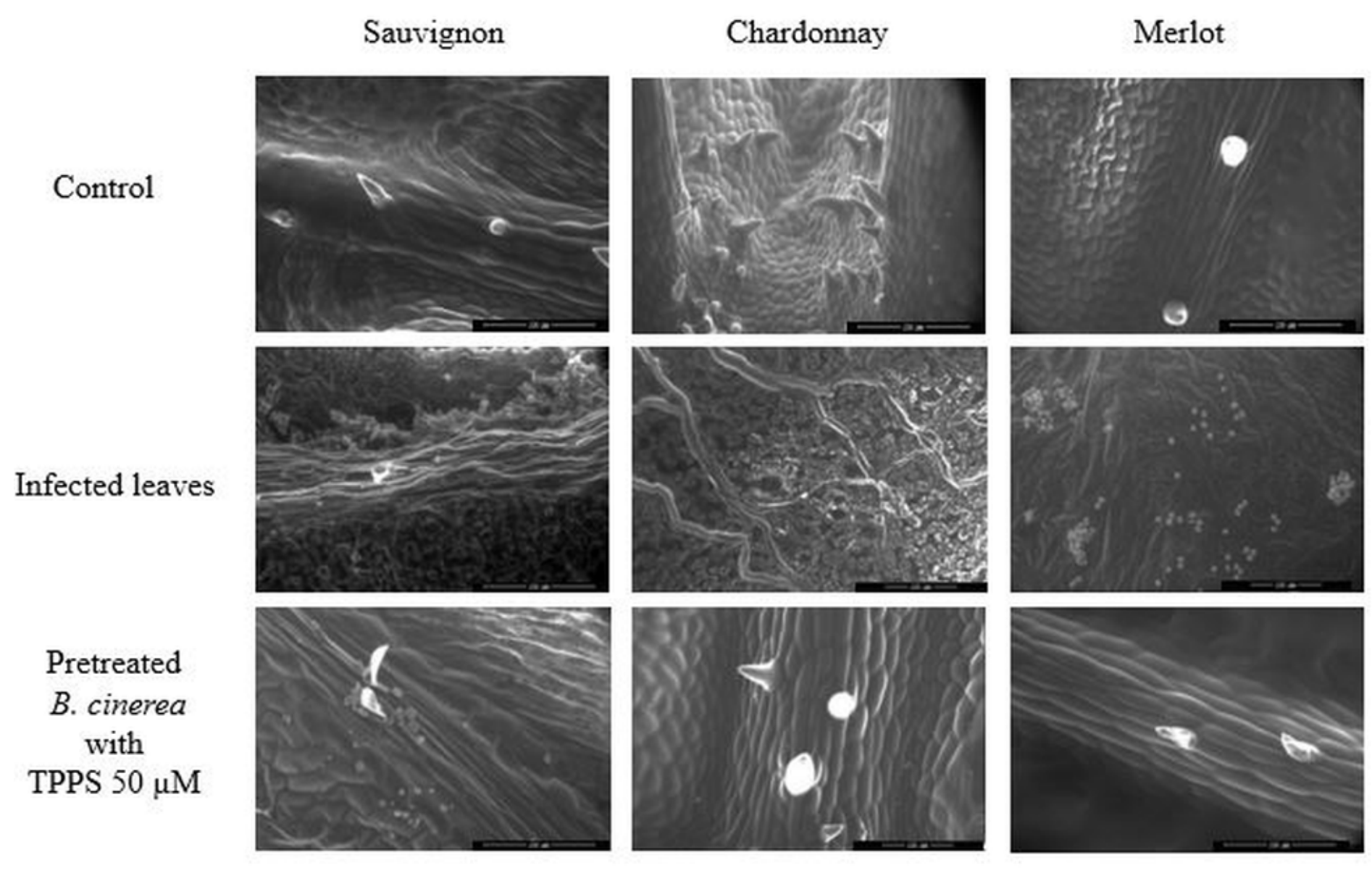

Figure 6

Scanning microscopy observations of leaves infected or not by B. cinerea pretreated or not with TPPS. After treatment with TPPS, the fungus was unable to infect the Chardonnay and Merlot leaves. For the Sauvignon variety, spores have been observed on leaf surface, even after TPPS pretreatment.

\section{Supplementary Files}

This is a list of supplementary files associated with this preprint. Click to download.

- AmbrosinietalTable1.docx

- AmbrosinietalTable2.docx 